\title{
Field evaluation of two commercial mosquito traps baited with different attractants and colored lights for malaria vector surveillance in Thailand
}

\author{
Alongkot Ponlawat ${ }^{1 *}$, Patcharee Khongtak ${ }^{1}$, Boonsong Jaichapor ${ }^{1}$, Arissara Pongsiri ${ }^{1}$ and Brian P. Evans ${ }^{2}$
}

\begin{abstract}
Background: Sampling for adult mosquito populations is a means of evaluating the efficacy of vector control operations. The goal of this study was to evaluate and identify the most efficacious mosquito traps and combinations of attractants for malaria vector surveillance along the Thai-Myanmar border.

Methods: In the first part of the study, the BG-Sentinel ${ }^{\mathrm{TM}}$ Trap (BGS Trap) and Centers for Disease Control and Prevention miniature light trap (CDC LT) baited with different attractants (BG-lure ${ }^{\oplus}$ and $\mathrm{CO}_{2}$ ) were evaluated using a Latin square experimental design. The six configurations were BGS Trap with BG-lure, BGS Trap with BG-lure plus $\mathrm{CO}_{2}$, BGS Trap with $\mathrm{CO}_{2}$, CDC LT with BG-lure, CDC LT with BG lure plus $\mathrm{CO}_{2}$, and CDC LT with $\mathrm{CO}_{2}$. The second half of the study evaluated the impact of light color on malaria vector collections. Colors included the incandescent bulb, ultraviolet (UV) light-emitting diode (LED), green light stick, red light stick, green LED, and red LED.

Results: A total of 8638 mosquitoes consisting of 42 species were captured over 708 trap-nights. The trap types, attractants, and colored lights affected numbers of female anopheline and Anopheles minimus collected $(G L M, P<0.01)$. Results revealed that BGS Trap captured many anophelines but was significantly less than the CDC LT. The CDC LT, when baited with BG-lure plus $\mathrm{CO}_{2}$ captured the greatest number of anopheline females with a catch rate significantly higher than the CDC LT baited with $\mathrm{BG}$-lure or $\mathrm{CO}_{2}$ alone $(P<0.05)$. The number of anopheline females collected from the CDC LT baited with $\mathrm{CO}_{2}$ was greater than the CDC LT baited with BG-lure (646 vs 409 females). None of the alternative lights evaluated exceeded the performance of the incandescent light bulb in terms of the numbers of anopheline and An. minimus collected.

Conclusion: We conclude that the CDC LT augmented with an incandescent light shows high potential for malaria vector surveillance when baited with $\mathrm{CO}_{2}$ and the BG-lure in combination and can be effectively used as the new gold standard technique for collecting malaria vectors in Thailand.
\end{abstract}

Keywords: Anopheles, BG sentinel, CDC light trap, Colored lights, Attractant

\footnotetext{
* Correspondence: AlongkotP.fsn@afrims.org

'Vector Biology and Control Section, Department of Entomology, Armed

Forces Research Institute of Medical Sciences (AFRIMS), Bangkok, Thailand

Full list of author information is available at the end of the article
} 


\section{Background}

While the international community has expedited efforts in recent years to control the spread of malaria, the disease remains endemic in 106 countries with one-fifth of the world's population (1.2 billion people) living in areas with a known high risk of disease transmission [1]. However, within the Greater Mekong Subregion (GMS) of Southeast Asia, an actual decline in malaria incidence and deaths over the previous decade provides some degree of optimism. Regardless, serious concern remains towards the prevalence of multidrug resistance in this region. An added challenge is the presence of "border malaria" cases which has proven exceptionally difficult to monitor and yet poses as a threat to the interior of countries such as Thailand where malaria had been successfully marginalized to the borders several decades prior [2, 3]. Adding to the distress are the complex socio-political issues that have continued to plague the region over decades which only serve to stifle efforts to control the spread of the disease within the region [4]. The situation is further compounded by the fact that all six Plasmodium species associated with humans are found within the GMS and additionally, the parasite is vectored by three Anopheles species complexes (An. minimus, $A n$. dirus and An. maculatus) with significant ecological variation to be found among and within the complexes [4]. To this end, an effective malaria surveillance program that includes monitoring for human cases, the parasites of interest, and the existence of potential or known vectors is vital to achieving effective health interventions and in evaluating possible impacts on malaria transmission.

Historically, human landing catches (HLCs) were used to survey for the existence of potential vectors of disease and to evaluate the efficacy of vector control operations. Data collected using this technique tended to provide a true sense of potential mosquito vector species and densities since the actual host was the bait. Data from HLCs could also be used to determine entomological inoculation rates, which are true estimates of the disease risk posed to humans [5-7]. However, the ethical issue of placing humans at greater risk for contracting disease, the labor-intensive aspects of the approach and the variation often found among "human attractants" justifies the need for alternative tools that are relatively safer and require minimal man-hours to operate.

To avoid human contact with mosquitoes, various devices have been developed over the years to survey for Anopheles mosquitoes [5, 8-12]. The BG Sentinel ${ }^{\mathrm{Tm}}$ Trap (BGS Trap) (Biogents, A.G. Regensburg, Germany) complemented with the BG lure (Biogents A.G.) [13], has shown significant promise as a tool for collecting $A e$. aegypti (L.) [13-16], Ae. albopictus (Skuse) [17], Culex pipiens L. [15] and Anopheles mosquitoes [18-21]. The BG-lure is a dispenser consisting of a blend of mosquito attractants (lactic acid, ammonia, and caproic acid). To date, the BGS Trap has not been field-tested in southeast Asia for anophelines and therefore no information on its efficacy in collecting malaria vectors from Thailand is available. In the current study, we evaluate the efficacy of the BGS Trap (baited with either $\mathrm{CO}_{2}$ or the BG-lure or both candidate attractants) compared with the Centers for Disease Control and Prevention (CDC) Miniature light trap Model 512 (CDC LT) (John W. Hock Company, Gainesville, FL, USA) under field conditions in Thailand.

We further evaluate the relative impact of colored lights on the collection of Anopheles spp. when used in conjunction with either the CDC or the BGS Trap. Ultraviolet (UV), blue, and green color are visible by insects [22-24]. Red and infrared light are invisible to most insects [24]. However, the majority of mosquito light traps are augmented with incandescent light bulbs which weakly emit the insect visible light spectra [25]. We hypothesized that insect-visible lights (UV, green) would improve the efficacy of mosquito traps by increasing the catch rate relative to invisible or weakly visible lights (incandescent and red). Data from this study may provide preliminary evidence that the incorporation of colored lights into the trap design will lead to an improved surveillance tool.

\section{Methods \\ Study site}

Trap comparison experiments were carried out in a malaria-endemic area located in Khun Huay, a village of over 100 non-enclosed homes, located in Mae Sot District, Tak Province in northwestern Thailand along the Thai-Myanmar border $\left(16^{\circ} 43^{\prime} 14^{\prime \prime} \mathrm{N}, 98^{\circ} 39^{\prime} 45^{\prime \prime} \mathrm{E}\right.$, Fig. 1). Residents are either Thai or Karen (from Myanmar) subsistence farmers of rice, maize, and soybean and rear livestock including cattle, pigs, and goats. The region is characterized by three seasons: rainy (mid-May to mid-September), winter (mid-September to mid-February), and summer (mid-February to mid-May). The current study was carried out from June to December 2010 with mean daily temperatures ranging between 22.4 and $29.8{ }^{\circ} \mathrm{C}$.

\section{Experimental design \\ Comparative field evaluation of BGS-trap and CDC LT}

Field evaluations were carried out using the BGS Trap and CDC LT. Six trap configurations were evaluated using a Latin square design as follows: (i) BGS Trap with BG-lure; (ii) BGS Trap with BG-lure plus $\mathrm{CO}_{2}$; (iii) BGS Trap with $\mathrm{CO}_{2}$; (iv) CDC LT with BG-lure; (v) CDC LT with BG-lure plus $\mathrm{CO}_{2}$; and (vi) CDC LT with $\mathrm{CO}_{2}$, respectively. Traps and attractants were operated according to manufacturers' instructions. Note that for the 


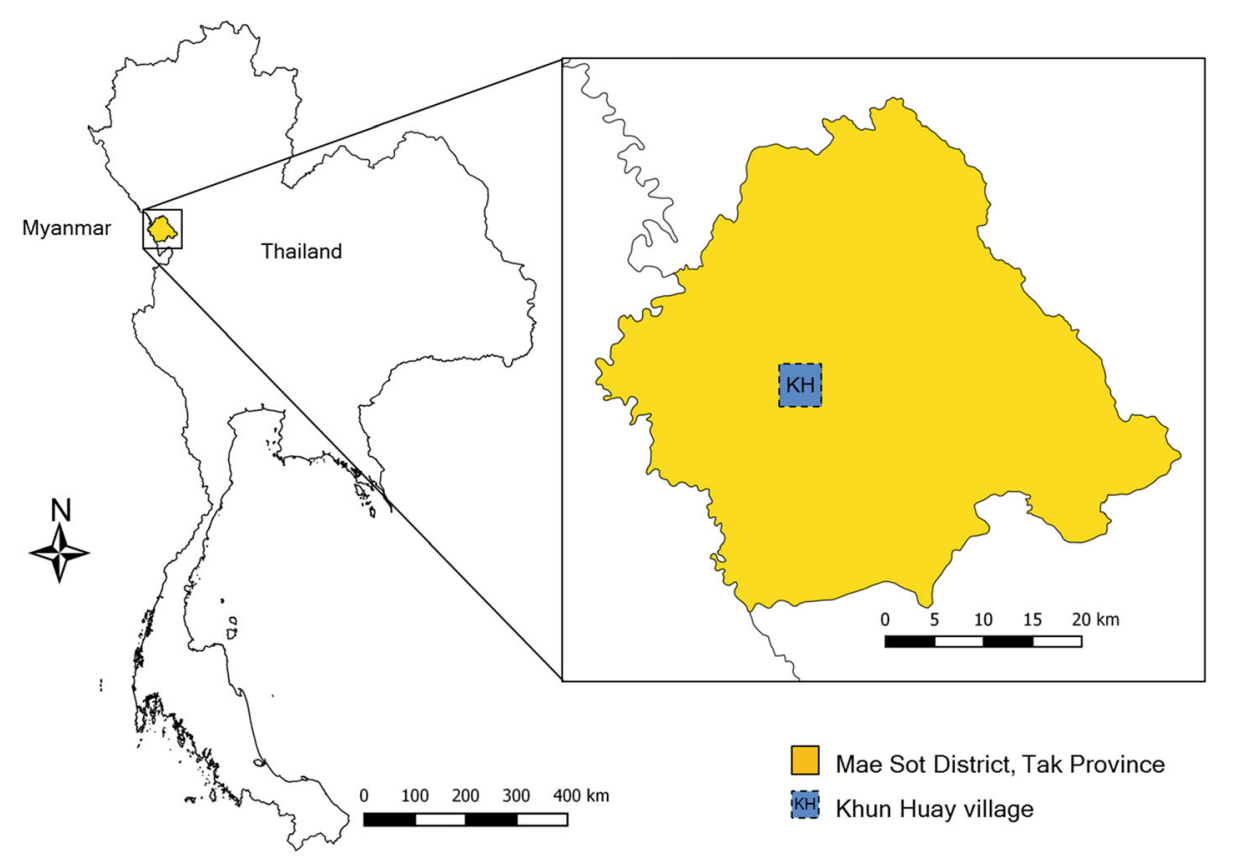

Fig. 1 The study site at Khun Huay village along the Thai-Myanmar boarder in Mae Sot District, Tak Province, Thailand

present study, the BGS Trap did not contain the BGlure unless specified. Dry ice (1 kg per trap) placed in an insulated plastic container with a release pipe was used as the $\mathrm{CO}_{2}$ source.

The village was divided into 6 cluster areas. Within each cluster area, 3 traps were operated for one particular trap configuration from 18:00 to 6:00 $\mathrm{h}$ with each trap in the cluster area separated by distances of at least $200 \mathrm{~m}$. Therefore, for one collection night, a total of 18 traps was operated across the 6 clusters representing all 6 configurations. To account for position effects, the 3 traps for one particular configuration were rotated counterclockwise to the adjoining cluster prior to sampling the subsequent night.

Collected mosquitoes were placed on dry ice for subsequent identification. Females were morphologically identified to species [26] and parity was determined.

\section{Efficacy evaluation of BGS trap and CDC LT augmented with different colored lights}

The efficacies of the BGS Trap and CDC LT (both trap types baited with BG-lure plus $\mathrm{CO}_{2}$ ) augmented with different light sources including light bulbs, light sticks and light-emitting diodes (LED) were evaluated for collecting anopheline mosquitoes. Four light configurations were evaluated for the BGS Trap: (i) incandescent bulb; (ii) UV LED; (iii) green light stick; and (iv) red light stick. For the CDC LT evaluation, four light configurations were tested: (i) incandescent bulb; (ii) UV LED; (iii) green LED; and (iv) red LED (Fig. 2). The 1.5-watt incandescent light (Chicago Miniature Lighting, Hackensack, NJ) was used as the control in this experiment. Colored LED light bulbs (UV, green, and red) were purchased from the local market in Thailand (Budget LED, Bangkok, Thailand). Four LED bi-pin bulbs of the same color arranged in a circular alignment were connected to each LED trap (Fig. 2). Six-inch green and red chemical light sticks rated for $12 \mathrm{~h}$ were used for the BGS Trap's light source (LC Industries, Durham, NC). The light sticks were waterproof, non-toxic and non-flammable light sources emitting a 360-degree bright light.

The village was divided into two areas; one area was used to evaluate the BG Trap configurations and the other area was used for the CDC LT configurations. Each area was further divided into a set of four cluster areas. Within each cluster area, two traps, separated by approximately $200 \mathrm{~m}$, were operated for one particular light configuration from 18:00 to 6:00 h. Therefore, for one collection night, 16 traps were operated across the 8 clusters representing all 8 configurations. Traps within each of the two areas (BGS Trap or CDC LT) were rotated counterclockwise after each of four collection days, comprising one replicate of the study. Six replicates were conducted. All collected samples were maintained in a cold chain (dry ice) upon transport to the field laboratory. Collected mosquitoes were separated by sex and enumerated. Collected females were morphologically identified to species and the parity rate was determined. 


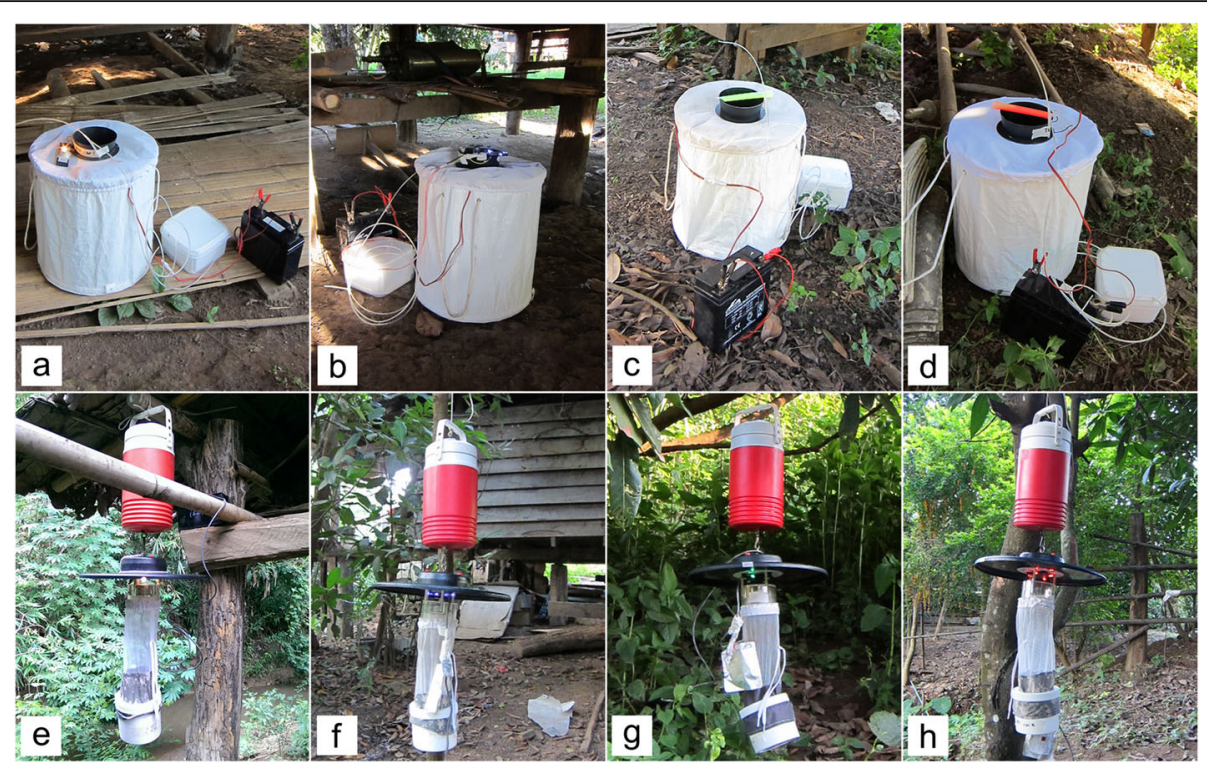

Fig. 2 Trap setting. a BGS trap with incandescent bulb. b BGS trap with UV LED. c BGS trap with green light stick. d BGS trap with red light stick, I CDC LT with incandescent bulb. $\mathbf{f}$ CDC LT with UV LED. $\mathbf{g}$ CDC LT with green LED. $\mathbf{h}$ CDC LT with red LED

\section{Physiological state determination}

After identification to species, Anopheles females were dissected under a microscope and classified as either nulliparous (coiled tracheole skeins visible in the ovaries), recently blood-fed (blood in the midgut), gravid (ovarioles developed past stage II), or parous (absence of tracheolar skeins in ovaries) [27].

\section{Data analysis}

All statistical analyses were performed using IBM SPSS statistical software, version 23. Total number of Anopheles and An. minimus Theobald females captured from each trap configuration were pooled by night (either 2 or 3 traps/trap configuration/night) for statistical analysis. Generalized linear model (GLM) with negative binomial error and log link function was used to analyze effects of trap configurations, different attractants and colored lights on the numbers of mosquitoes collected in both experiments. The dispersion coefficients were estimated using maximum likelihood estimation. Parameter coefficients were tested using Wald Chi-square. Incident rate ratios (IRR) of BGS Trap, tested attractants, and colored lights were calculated relative to CDC LT with $\mathrm{CO}_{2}$ and incandescent light as the reference. The values of IRR greater or lower than 1 indicate higher or lower trapping performance relative to the reference one. The hypothesis was tested using the Chi-square $\left(\chi^{2}\right)$. The physiological state (parity rate) was determined and calculated as a percentage of parous females from the total mosquitoes dissected. The Chi-square $\left(\chi^{2}\right)$ test was used to statistically analyze the physiological state data.

\section{Results}

Comparative field evaluation of BGS-trap and CDC LT

A total of 42 mosquito species (6079 female mosquitoes) was collected. From the collections spanning 324 trapnights, the predominant species were $C x$. vishnui Theobald (28.66\%), An. minimus (25.86\%) and Cx. quinquefasciatus Say (12.22\%). The BGS Trap (with $\mathrm{CO}_{2}$, BG-lure, or both) and CDC LT (with $\mathrm{CO}_{2}$, BG-lure, or both) collected $1676(27.57 \%)$ and 4403 (72.43\%) female mosquitoes, respectively (Table 1). The BGS Trap collected a total of 30 mosquito species while the CDC LT collected 38 mosquito species. The predominant species collected by the BGS Trap were $C x$. quinquefasciatus $(n=685), C x$. vishnui ( $n=354)$, An. minimus $(n=241)$, An. vagus Doenitz ( $n=143)$ and Ae. albopictus $(n=88)$. Species most commonly found in the CDC LT included An. minimus $(n=1340)$, Cx. vishnui $(n=1388)$, Ae. vexans (Meigen) ( $n=395)$, An. sawadwongporni Rattanarithikul \& Green $(n=162)$, An. vagus $(n=162), C x$. gelidus Theobald $(n=157)$, Ae. vigilax (Skuse) $(n=144)$ and An. splendidus Koidzumi $(n=119)$. Notably, the CDC LT trapped more species and greater numbers of anthropophilic malaria vectors such as An. minimus, An. vagus, An. sawadwongporni and An. splendidus than the BGS-Trap (Table 1).

Statistical analysis revealed that trap type and attractants affected numbers of female anopheline and $A n$. minimus collections (Table 2). The performance of the BGS Trap for collecting female anopheline and $A n$. minimus was significantly lower than CDC LT (female anopheline: $\chi^{2}=60.207, d f=1, P<0.0001 ; A n$. minimus: $\chi^{2}=71.333, d f=1, P<0.0001$ ) (Table 2). The combination of BG-lure and $\mathrm{CO}_{2}$ as the trap attractants tended 
Table 1 Total numbers of female mosquitoes collected from each tested trap configuration from both experiments conducted in Khun Huay, Mae Sot District, Tak Province, from June to December 2010

\begin{tabular}{|c|c|c|c|c|c|c|c|c|}
\hline & Trap type & Tested attractant & Trap-night & Anopheles & An. minimus & Aedes & Culex & Others $^{\mathrm{a}}$ \\
\hline \multirow[t]{6}{*}{ Exp. 1} & \multirow[t]{3}{*}{ CDC LT } & $\mathrm{CO}_{2}$ & 54 & 646 & 412 & 347 & 673 & 24 \\
\hline & & BG-lure $+\mathrm{CO}_{2}$ & 54 & 973 & 693 & 207 & 999 & 25 \\
\hline & & BG-lure & 54 & 409 & 230 & 11 & 82 & 7 \\
\hline & \multirow[t]{3}{*}{ BGS Trap } & $\mathrm{CO}_{2}$ & 54 & 204 & 90 & 39 & 457 & 11 \\
\hline & & $\mathrm{BG}$-lure $+\mathrm{CO}_{2}$ & 54 & 204 & 132 & 60 & 375 & 16 \\
\hline & & BG-lure & 54 & 41 & 15 & 16 & 248 & 5 \\
\hline \multirow[t]{8}{*}{ Exp. II } & \multirow[t]{4}{*}{ CDC LT } & Incandescent & 48 & 585 & 189 & 2 & 25 & 48 \\
\hline & & UV LED & 48 & 448 & 127 & 10 & 23 & 20 \\
\hline & & Green LED & 48 & 298 & 79 & 6 & 5 & 21 \\
\hline & & Red LED & 48 & 410 & 168 & 6 & 6 & 11 \\
\hline & \multirow[t]{4}{*}{ BGS Trap } & Incandescent & 48 & 96 & 34 & 49 & 24 & 31 \\
\hline & & UV LED & 48 & 81 & 12 & 10 & 41 & 73 \\
\hline & & Green light stick & 48 & 43 & 5 & 27 & 13 & 29 \\
\hline & & Red light stick & 48 & 27 & 3 & 36 & 26 & 27 \\
\hline
\end{tabular}

${ }^{a}$ Others include mosquitoes in 5 genera (Armigeres, Downsiomyia, Lutzia, Uranotaenia and Mansonia)

to enhance anopheline and An. minimus collections (IRR $=1.20$ and 1.57$)$ albeit not significantly. The addition of BG-lure to the gold standard technique for malaria vector collection (CDC LT with $\mathrm{CO}_{2}$ ) increases the effectiveness of sampling for Anopheles (IRR $=1.72, P=0.041$ ) and An. minimus (IRR $=1.99, P=0.013$ ) (Table 3). Interestingly, comparison of efficacies (Anopheles collection) between CDC LT baited with either $\mathrm{CO}_{2}$ or BG-lure alone revealed no statistically significant differences (IRR $=0.67$, $P=0.135)$. The current field study shows that the BGlure, when used in concert with $\mathrm{CO}_{2}$, can significantly enhance Anopheles and An. minimus CDC LT collections relative to the CDC LT with just $\mathrm{CO}_{2}$.

Within the BGS Trap collections, we found that augmentation with $\mathrm{CO}_{2}$ can improve the efficacy of the trap for malaria vector collections. The number of Anopheles collected by BGS Traps augmented with $\mathrm{CO}_{2}$ was significantly higher than BGS Trap baited only with BGlure $\left(\chi^{2}=34.554, d f=1, P<0.0001\right.$, Table 3$)$. However, the efficacy of BGS-Trap baited with $\mathrm{CO}_{2}$ was not significantly different from the trap baited with BG-lure plus $\mathrm{CO}_{2}$ for Anopheles capture $(P=0.92)$. For An. minimus collections, adding BG-lure into the BGS Trap baited with $\mathrm{CO}_{2}$ significantly improved the trap efficacy (IRR $=1.55, P=0.046$, Table 3$)$.

Age grading and blood meal status identification took place for a total of 2477 Anopheles females (Table 4). Almost all of the females were found to be in the empty stage (99.1\%). Notably, nearly half of the samples captured by the BGS Trap baited with BG-lure were recently blood-fed specimens $(41.5 \%, n=17)$. Parity rates of Anopheles mosquitoes collected by BGS-Trap and

Table 2 The efficacy of the BGS trap and different attractants relative to the CDC LT and $\mathrm{CO}_{2}$ for collecting anophelines and An. minimus

\begin{tabular}{|c|c|c|c|c|c|}
\hline & Treatment & IRR & $95 \% \mathrm{Cl}$ & $x^{2}$ & $P$-value \\
\hline \multirow[t]{5}{*}{ q Anopheline } & CDC light trap (reference) & & & & \\
\hline & BG-sentinel & 0.19 & $0.13-0.29$ & 60.21 & $<0.0001$ \\
\hline & $\mathrm{CO}_{2}$ (reference) & & & & \\
\hline & $\mathrm{BG}$-lure $+\mathrm{CO}_{2}$ & 1.20 & $0.74-1.97$ & 0.54 & 0.462 \\
\hline & BG-lure & 0.38 & $0.23-0.63$ & 13.80 & $<0.0001$ \\
\hline \multirow[t]{5}{*}{ o An. minimus } & CDC light trap (reference) & & & & \\
\hline & BG-sentinel & 0.15 & $0.10-0.23$ & 71.33 & $<0.0001$ \\
\hline & $\mathrm{CO}_{2}$ (reference) & & & & \\
\hline & $\mathrm{BG}$-lure $+\mathrm{CO}_{2}$ & 1.57 & $0.94-2.61$ & 2.98 & 0.084 \\
\hline & BG-lure & 0.36 & $0.21-0.61$ & 13.93 & 0.002 \\
\hline
\end{tabular}


Table 3 The efficacy of different attractants (for each trap type) relative to the $\mathrm{CO}_{2}$ for collecting anophelines and An. minimus

\begin{tabular}{|c|c|c|c|c|c|c|}
\hline & & Treatment & IRR & $95 \% \mathrm{Cl}$ & $x^{2}$ & $P$-value \\
\hline \multirow[t]{6}{*}{$\overline{C D C ~ L T}$} & q Anopheline & $\mathrm{CO}_{2}$ (reference) & & & & \\
\hline & & BG-lure $+\mathrm{CO}_{2}$ & 1.72 & $1.02-2.88$ & 4.19 & 0.041 \\
\hline & & BG-lure & 0.67 & $0.40-1.13$ & 2.23 & 0.135 \\
\hline & q An. minimus & $\mathrm{CO}_{2}$ (reference) & & & & \\
\hline & & BG-lure $+\mathrm{CO}_{2}$ & 1.99 & $1.16-3.41$ & 6.19 & 0.013 \\
\hline & & BG-lure & 0.63 & $0.36-1.09$ & 2.74 & 0.098 \\
\hline \multirow[t]{6}{*}{ BGS-Trap } & o Anopheline & $\mathrm{CO}_{2}$ (reference) & & & & \\
\hline & & $\mathrm{BG}$-lure $+\mathrm{CO}_{2}$ & 1.02 & $0.66-1.60$ & 0.01 & 0.917 \\
\hline & & BG-lure & 0.19 & $0.11-0.33$ & 34.55 & $<0.0001$ \\
\hline & q An. minimus & $\mathrm{CO}_{2}$ (reference) & & & & \\
\hline & & $\mathrm{BG}$-lure $+\mathrm{CO}_{2}$ & 1.55 & $1.01-2.39$ & 4.00 & 0.046 \\
\hline & & BG-lure & 0.18 & $0.09-0.34$ & 27.65 & $<0.0001$ \\
\hline
\end{tabular}

Abbreviations: IRR estimated incident rate ratio, $\mathrm{Cl}$ confidence interval, corresponding $P$-value based on maximum likelihood estimation of GLM with negative binomial error and log link function

CDC LT baited with different attractants ranged from 31.7 to $44.1 \%$. No significant differences could be detected $\left(\chi^{2}=5.79, P=0.33\right.$, Table 4$)$.

\section{Efficacy evaluation of BGS trap and CDC LT augmented with different colored lights}

For over 384 trap-nights, a total of 2557 female mosquitoes were captured representing 41 species in 11 genera including Anopheles, Armigeres, Culex, Aedes, Bothaella, Lorrainea, Downsiomyia, Malaya, Mansonia, Uranotaenia and Heizmannia (Table 1). Anopheles spp. were the most abundant $(77.7 \%$ of the total collected mosquitoes, $n=1988)$. Seventeen Anopheles species were collected of which An. minimus was predominant $(n=1490)$. The BGS-Trap (all configurations) and CDC LT (all configurations) trapped 633 and 1924 mosquito females, respectively (Table 1 ). The main species collected by the BGS Trap were An. minimus $(n=164)$, Ar. subalbatus (Coquillett) ( $n=137)$, Ae. albopictus ( $n=100), C x$. vishnui $(n=85)$ and An. peditaeniatus (Leicester) $(n=55)$ while the common species collected by CDC LT were An. minimus $(n=1326)$, An. peditaeniatus
( $n=276)$, Ar. subalbatus $(n=89)$ and An. tessellatus Theobald $(n=44)$. All totaled, a greater number of anophelines was attracted to the CDC LT configurations than the BGS Trap configurations.

The trap type, and different colored lights significantly influenced the number of female anophelines (GLM, $\chi^{2}=130.261, d f=1, P<0.0001$ and $\chi^{2}=13.082, d f=3$, 0.004 , respectively) and the number of An. minimus collected (GLM, $\chi^{2}=120.678, d f=1, P<0.0001$ and $X^{2}=12.237, d f=3,0.007$, respectively). Significantly lower numbers of female anophelines and $A n$. minimus were collected by the BGS Trap relative to the CDC LT (Table 5). None of the colored lights tested could exceed the performance of incandescent bulbs as conventional light sources for CDC LT (Table 5). An overview of the results showed the order of trap efficiency as incandescent $>\mathrm{UV}>$ green > red. As expected, the number of female anopheline (IRR $=0.50, P=0.004)$ and An. minimus (IRR $=0.43, P=0.002$ ) collected were significantly lower when traps were augmented with red light (Table 5).

Within the CDC LT group, significantly fewer anophelines were collected when green $(\mathrm{IRR}=0.56, P=0.001)$

Table 4 Percentage of female Anopheles (actual number) in different physiological conditions collected from each trap configuration and the parity rate for each trap configuration

\begin{tabular}{|c|c|c|c|c|c|c|c|}
\hline \multirow[t]{2}{*}{ Physiological condition } & \multicolumn{3}{|l|}{ BGS-Trap } & \multicolumn{3}{|l|}{ CDC LT } & \multirow[t]{2}{*}{ Grand total } \\
\hline & BG-lure & BG-lure $+\mathrm{CO}_{2}$ & $\mathrm{CO}_{2}$ & BG-lure & BG-lure $+\mathrm{CO}_{2}$ & $\mathrm{CO}_{2}$ & \\
\hline Nulliparous & $19.5(8)$ & $55.4(113)$ & $63.7(130)$ & $64.6(264)$ & $62.9(612)$ & $64.1(414)$ & $62.2(1541)$ \\
\hline Parous & $31.7(13)$ & $44.1(90)$ & $35.8(73)$ & $35.5(145)$ & $37.0(360)$ & $35.9(232)$ & $36.9(913)$ \\
\hline Gravid & $7.3(3)$ & $0.5(1)$ & $0.5(1)$ & $0(0)$ & $0(0)$ & $0(0)$ & $20.2(5)$ \\
\hline Recently blood-fed & $41.5(17)$ & $0(0)$ & $0(0)$ & $0(0)$ & $0(1)$ & $0(0)$ & $0.7(18)$ \\
\hline Total & 41 & 204 & 204 & 409 & 973 & 646 & 2477 \\
\hline Parity rate (\%) & 31.7 & 44.1 & 35.8 & 35.5 & 37.0 & 36.0 & \\
\hline
\end{tabular}


Table 5 Efficacy of BGS trap and different colored lights relative to the CDC LT and the incandescent light for capturing anophelines and An. minimus females

\begin{tabular}{|c|c|c|c|c|c|}
\hline & Treatment & IRR & $95 \% \mathrm{Cl}$ & $x^{2}$ & $P$-value \\
\hline \multirow[t]{6}{*}{ q Anopheline } & CDC light trap (reference) & & & & \\
\hline & BG-sentinel & 0.13 & $0.09-0.19$ & 130.26 & $<0.0001$ \\
\hline & Incandescent (reference) & & & & \\
\hline & UV (10-400 nm wavelength) & 0.80 & $0.50-1.29$ & 0.83 & 0.363 \\
\hline & Green (490-570 nm wavelength) & 0.48 & $0.30-0.77$ & 9.12 & 0.003 \\
\hline & Red (620-780 nm wavelength) & 0.50 & $0.31-0.81$ & 8.09 & 0.004 \\
\hline \multirow[t]{6}{*}{ q An. minimus } & CDC light trap (reference) & & & & \\
\hline & BG-sentinel & 0.11 & $0.08-0.17$ & 120.68 & $<0.0001$ \\
\hline & Incandescent (reference) & & & & \\
\hline & UV (10-400 nm wavelength) & 0.81 & $0.48-1.37$ & 0.61 & 0.436 \\
\hline & Green (490-570 nm wavelength) & 0.51 & $0.30-0.87$ & 6.14 & 0.013 \\
\hline & Red (620-780 nm wavelength) & 0.43 & $0.25-0.74$ & 9.37 & 0.002 \\
\hline
\end{tabular}

Abbreviations: IRR estimated incident rate ratio, $C$ confidence interval, corresponding $P$-value based on maximum likelihood estimation of GLM with negative binomial error and log link function

and red lights (IRR $=0.56, P=0.001)$ were used as light sources when compared to the numbers collected by the control (incandescent light). Significantly fewer $A n$. minimus were collected when green $(\mathrm{IRR}=0.55$, $P=0.001$,) and red lights (IRR $=0.57, P=0.002$ ) were used as light sources when compared to the numbers collected by the control (Table 6). However, analysis of the results demonstrated lower catch rates of anopheline females $(\mathrm{IRR}=0.74)$ and An. minimus $(\mathrm{IRR}=0.81)$ in the UV light relative to the incandescent light, although no significant differences were statistically detected.

A similar significant effect of different light colors was observed within the BGS Trap configurations. No significant differences were detected in UV light augmented traps compared to the control $(P>0.05$, Table 6). However, significantly lower capture numbers of malaria vectors in green and red colored lights relative to the incandescent light were detected $(P<0.001)$.

Table 6 Efficacy of different colored lights (for each trap type) relative to the incandescent light for collecting anophelines and An. minimus

\begin{tabular}{|c|c|c|c|c|c|c|}
\hline & & Treatment & IRR & $95 \% \mathrm{Cl}$ & $x^{2}$ & P-value \\
\hline \multirow[t]{8}{*}{ CDC LT } & q Anopheline & Incandescent (reference) & & & & \\
\hline & & UV (10-400 nm wavelength) & 0.74 & $0.53-1.03$ & 3.11 & 0.078 \\
\hline & & Green (490-570 nm wavelength) & 0.56 & $0.40-0.79$ & 10.99 & 0.001 \\
\hline & & Red (620-780 nm wavelength) & 0.56 & $0.40-0.78$ & 11.54 & 0.001 \\
\hline & q An. minimus & Incandescent (reference) & & & & \\
\hline & & UV (10-400 nm wavelength) & 0.81 & $0.56-1.15$ & 1.42 & 0.233 \\
\hline & & Green (490-570 nm wavelength) & 0.55 & $0.38-0.79$ & 10.38 & 0.001 \\
\hline & & Red (620-780 nm wavelength) & 0.57 & $0.40-0.82$ & 9.27 & 0.002 \\
\hline \multirow[t]{8}{*}{ BGS Trap } & q Anopheline & Incandescent (reference) & & & & \\
\hline & & UV (10-400 nm wavelength) & 0.66 & $0.38-1.13$ & 2.28 & 0.131 \\
\hline & & Green (490-570 nm wavelength) & 0.27 & $0.14-0.51$ & 16.4 & $<0.0001$ \\
\hline & & Red (620-780 nm wavelength) & 0.31 & $0.16-0.58$ & 13.05 & $<0.0001$ \\
\hline & † An. minimus & Incandescent (reference) & & & & \\
\hline & & UV (10-400 nm wavelength) & 0.54 & $0.28-1.04$ & 3.43 & 0.064 \\
\hline & & Green (490-570 nm wavelength) & 0.22 & $0.10-0.48$ & 14.35 & $<0.0001$ \\
\hline & & Red (620-780 nm wavelength) & 0.17 & $0.07-0.40$ & 16.60 & $<0.0001$ \\
\hline
\end{tabular}


Table 7 Percentage of Anopheles female (actual number) in different physiological conditions captured from 8 different colored-light trap configurations and the parity rate for each trap configuration

\begin{tabular}{|c|c|c|c|c|c|c|c|c|c|}
\hline \multirow[t]{2}{*}{ Physiological condition } & \multicolumn{4}{|l|}{ BGS-Trap } & \multicolumn{4}{|l|}{ CDC LT } & \multirow[t]{2}{*}{ Grand tota } \\
\hline & Incandescent & UV LED & Green light stick & Red light stick & Incandescent & UV LED & Green LED & Red LED & \\
\hline Nulliparous & $55.2(53)$ & $49.4(40)$ & $62.8(27)$ & $44.4(12)$ & $51.8(303)$ & $51.8(232)$ & $55.7(166)$ & $54.9(225)$ & $53.2(1058)$ \\
\hline Parous & $43.8(42)$ & $48.2(39)$ & $37.2(16)$ & $55.6(15)$ & $46.5(272)$ & $45.1(202)$ & $43.3(129)$ & $44.2(181)$ & $45.1(896)$ \\
\hline Gravid & $0(0)$ & $0(0)$ & $0(0)$ & $0(0)$ & $0(0)$ & $0(0)$ & $0(0)$ & $0(0)$ & $0(0)$ \\
\hline Recently blood-fed & $1.0(1)$ & $2.5(2)$ & $0(0)$ & $0(0)$ & $1.7(10)$ & $3.1(14)$ & $1.0(3)$ & $1.0(4)$ & $1.7(34)$ \\
\hline Total & 96 & 81 & 43 & 27 & 585 & 448 & 298 & 410 & 1988 \\
\hline Parity rate (\%) & 43.8 & 48.2 & 37.2 & 55.6 & 46.5 & 45.1 & 43.3 & 44.2 & \\
\hline
\end{tabular}

The physiological stage and blood meal status were determined for 1988 female Anopheles collected from the eight trap configurations. Most of the collected females were in the empty stage (98.3\%). Only $1.0-3.1 \%$ of adults collected from these traps contained blood. Parity rates of Anopheles mosquitoes collected by BGS-Trap and CDC LT baited with different colored-lights did not vary significantly, ranging from $37.2-55.6 \%\left(\chi^{2}=3.65\right.$, $P=0.82$ ) (Table 7).

\section{Discussion}

The present study represents the first field evaluation of the BGS Trap for capturing malaria vectors in Thailand and southeast Asia. Our findings demonstrated that the BGS Trap captured a variety of mosquitoes (30 species) during the night including important malaria vectors. However, results from this field study are similar to previous studies in which the CDC LT trapped significantly more mosquitoes and anopheline females than the BGS Trap and proved that mosquito species composition depends on trap type $[18,28,29]$. Moreover, important anthropophilic malaria vectors were caught by CDC LT. In addition to the design of the trap, trap height tends to play an important role in mosquito collections [30, 31].

Findings from the present study confirmed that CDC LT, when baited with BG-lure and $\mathrm{CO}_{2}$, yields higher numbers of anophelines and An. minimus than other trap configurations. Our results parallel a similar environmental chamber study which found that the combination of the BG-lure and $\mathrm{CO}_{2}$ proved to be most effective at attracting $A n$. gambiae [21]. Surprisingly, our results demonstrated no significant differences in anopheline catch numbers between the CDC LT baited with $\mathrm{CO}_{2}$ and the CDC LT baited with the BG-lure alone. Our findings revealed that the BG-lure can be used as a substitute for $\mathrm{CO}_{2}$ as the attractant for CDC LT in malaria-centric areas and in study sites where viable $\mathrm{CO}_{2}$ sources present a challenge. Our research has shown an equal proportion of parous females in each trap configuration suggesting that physiological stage does not make Anopheles prone to one particular trap.
The second objective of this study was to evaluate the efficacy of the BGS Trap and CDC LT when baited with different colored lights for capturing malaria vectors. Findings from the current study show the CDC LT (baited with BG-lure and $\mathrm{CO}_{2}$ ) augmented with an incandescent light is a favorable tool for malaria vector surveillance in Thailand and can be applied in other countries. Interestingly, not all insect visible lights attract Anopheles mosquitoes. Our results show that colored lights and trap type have no significant impact on the collections of different physiological stages of female Anopheles (both parous and nulliparous). The CDC LT augmented with an incandescent light bulb, BG-lure and $\mathrm{CO}_{2}$ is most effective and reliable in collecting anophelines and can be effectively used as the new gold standard technique to collect malaria vectors.

\section{Conclusion}

The CDC LT augmented with an incandescent light bulb, BG-lure and $\mathrm{CO}_{2}$ is most effective and reliable in collecting anophelines and can be effectively used as the new gold standard technique to collect malaria vectors. The BG-lure can be substituted for $\mathrm{CO}_{2}$ as an attractant in CDC LT in hard-to-reach malaria sites where $\mathrm{CO}_{2}$ sources are scarce. The BGS Trap can collect a variety of night-time feeding mosquitoes including important malaria vectors; however, the number of Anopheles collected is significantly lower than the CDC LT. The data presented here will assist researchers in selecting the most appropriate malaria vector surveillance tools.

\section{Abbreviations}

BGS: BG Sentinel ${ }^{\mathrm{TM}}$ trap; CDC LT: Centers for disease control and prevention miniature light trap; GLM: Generalized linear model; GMS: Greater Mekong Subregion; HLC: Human landing counts; IRR: Incident rate ratios; LED: Light-emitting diodes

\section{Acknowledgements}

We acknowledge the excellent support of villagers in the study site. This work was financially supported by the Military Infectious Disease Research Program - Identification and Control of Insect Vectors of Infectious Diseases (Task Area U). The views expressed herein are the private views of the authors and do not reflect the official views of the Department of the Army, Department of Defense, or the U.S. Government. 


\section{Funding}

This work was financially supported by the Military Infectious Disease Research Program - Identification and Control of Insect Vectors of Infectious Diseases (Task Area $U$ ). The funding agency played no role in the design or implementation of the study, analysis or interpretation of the data, or the preparation and submission of the manuscript.

\section{Availability of data and materials}

The datasets supporting the conclusions of this article are included within the article.

\section{Authors' contributions}

APL, PK and BPE designed the experiments. APL, PK and BJ performed the field experiments. BJ identified mosquito samples. APS analyzed the data. APL and BPE wrote the manuscript. All authors read and approved the final manuscript.

\section{Ethics approval and consent to participate}

Not applicable.

\section{Consent for publication}

Not applicable.

\section{Competing interests}

The authors declare that they have no competing interests.

\section{Publisher's Note}

Springer Nature remains neutral with regard to jurisdictional claims in published maps and institutional affiliations.

\section{Author details}

${ }^{1}$ Vector Biology and Control Section, Department of Entomology, Armed Forces Research Institute of Medical Sciences (AFRIMS), Bangkok, Thailand ${ }^{2}$ Armed Forces Pest Management Board, Silver Spring, MD, USA.

\section{Received: 5 May 2017 Accepted: 28 July 2017}

\section{Published online: 07 August 2017}

\section{References}

1. Alonso PL, Brown G, Arevalo-Herrera M, Binka F, Chitnis C, Collins F, et al. A research agenda to underpin malaria eradication. PLoS Med. 2011;8(1): e1000406.

2. Delacollette C, D'Souza C, Christophel E, Thimasarn K, Abdur R, Bell D, et al. Malaria trends and challenges in the greater Mekong subregion. Southeast Asian J Trop Med Public Health. 2009;40(4):674-91.

3. Cui L, Yan G, Sattabongkot J, Cao Y, Chen B, Chen X, et al. Malaria in the greater Mekong subregion: heterogeneity and complexity. Acta Trop. 2012; 121(3):227-39.

4. Parker DM, Carrara VI, Pukrittayakamee S, McGready R, Nosten FH. Malaria ecology along the Thailand-Myanmar border. Malar J. 2015;14:388.

5. Service MW. Mosquito ecology: field sampling methods. 2nd ed. London: Elsevier; 1993

6. Mboera LE. Sampling techniques for adult Afrotropical malaria vectors and their reliability in the estimation of entomological inoculation rate. Tanzan Health Res Bull. 2005;7(3):117-24.

7. Kilama M, Smith DL, Hutchinson R, Kigozi R, Yeka A, Lavoy G, et al. Estimating the annual entomological inoculation rate for Plasmodium falciparum transmitted by Anopheles gambiae s.l. using three sampling methods in three sites in Uganda. Malar J. 2014;13:111.

8. Sithiprasasna $R$, Jaichapor $B$, Chanaimongkol S, Khongtak $P$, Lealsirivattanakul T, Tiang-Trong $S$, et al. Evaluation of candidate traps as tools for conducting surveillance for Anopheles mosquitoes in a malariaendemic area in western Thailand. J Med Entomol. 2004;41(2):151-7.

9. Harris C, Kihonda J, Lwetoijera D, Dongus S, Devine G, Majambere S. A simple and efficient tool for trapping gravid Anopheles at breeding sites. Parasit Vectors. 2011;4:125.

10. Hiwat H, De Rijk M, Andriessen R, Koenraadt CJ, Takken W. Evaluation of methods for sampling the malaria vector Anopheles darlingi (Diptera, Culicidae) in Suriname and the relation with its biting behavior. J Med Entomol. 2011;48(5):1039-46.
11. Rubio-Palis Y, Moreno JE, Sanchez V, Estrada Y, Anaya W, Bevilacqua M, et al Can mosquito magnet(R) substitute for human-landing catches to sample anopheline populations? Mem Inst Oswaldo Cruz. 2012;107(4):546-9.

12. Maliti DV, Govella NJ, Killeen GF, Mirzai N, Johnson PC, Kreppel K, et al. Development and evaluation of mosquito-electrocuting traps as alternatives to the human landing catch technique for sampling host-seeking malaria vectors. Malar J. 2015;14:502

13. Krockel U, Rose A, Eiras AE, Geier M. New tools for surveillance of adult yellow fever mosquitoes: comparison of trap catches with human landing rates in an urban environment. J Am Mosq Control Assoc. 2006;22(2):229-38.

14. Maciel-de-Freitas R, Eiras AE, Lourenco-de-Oliveira R. Field evaluation of effectiveness of the BG-sentinel, a new trap for capturing adult Aedes aegypti (Diptera: Culicidae). Mem Inst Oswaldo Cruz. 2006;101(3):321-5.

15. Rose A, Kröckel U, Bergbauer R, Geier M, Eires ÁE. Der BG-Sentinel, eine neuartige Stechmückenfalle für Forschung und Überwachung. Mitteilungen Dtsch Ges Für Allg Angew Entomol. 2006;15:345-8.

16. Williams CR, Long SA, Russell RC, Ritchie SA. Field efficacy of the BG-sentinel compared with CDC backpack aspirators and CO2-baited EVS traps for collection of adult Aedes aegypti in Cairns, Queensland, Australia. J Am Mosq Control Assoc. 2006:22(2):296-300.

17. Meeraus WH, Armistead JS, Arias JR. Field comparison of novel and gold standard traps for collecting Aedes albopictus in northern Virginia. J Am Mosq Control Assoc. 2008;24(2):244-8.

18. Wagman J, Grieco JP, Bautista K, Polanco J, Briceno I, King R, et al. A comparison of two commercial mosquito traps for the capture of malaria vectors in northern Belize, central America. J Am Mosq Control Assoc. 2014; 30(3):175-83.

19. Gama RA, Silva IM, Geier M, Eiras AE. Development of the BG-malaria trap as an alternative to human-landing catches for the capture of Anopheles darlingi. Mem Inst Oswaldo Cruz. 2013;108(6):763-71.

20. Schmied WH, Takken W, Killeen GF, Knols BG, Smallegange RC. Evaluation of two counterflow traps for testing behaviour-mediating compounds for the malaria vector Anopheles gambiae s.s. under semi-field conditions in Tanzania. Malar J. 2008;7:230

21. Hoel DF, Marika JA, Dunford JC, Irish SR, Geier M, Obermayr U, et al. Optimizing collection of Anopheles gambiae s.s. (Diptera: Culicidae) in biogents sentinel traps. J Med Entomol. 2014:51(6):1268-75.

22. Briscoe AD, Chittka L. The evolution of color vision in insects. Annu Rev Entomol. 2001:46:471-510.

23. Burkett DA, Butler JF, Kline DL. Field evaluation of colored light-emitting diodes as attractants for woodland mosquitoes and other diptera in north central Florida. J Am Mosq Control Assoc. 1998;14(2):186-95.

24. Cohnstaedt LW, Gillen J, Munstermann LE. Light-emitting diode technology improves insect trapping. J Am Mosq Control Assoc. 2008;24(2):331-4.

25. Evans BP, Clark JW, Barbara KA, Mundal KD, Furman BD, McAvin JC, et al. Operational vector-borne disease surveillance and control: closing the capabilities gap through research at overseas military laboratories. US Army Med Dep J. 2009:2:16-27.

26. Rattanarithikul R, Harrison BA, Harbach RE, Panthusiri P, Coleman RE, Panthusiri P. Illustrated keys to the mosquitoes of Thailand. IV. Anopheles. Southeast Asian J Trop Med Public Health. 2006;37(Suppl 2):1-128.

27. Detinova TS. Age-grouping methods in Diptera of medical importance with special reference to some vectors of malaria. Monogr Ser World Health Organ. 1962:47:13-191.

28. Missawa NA, Ribeiro AL, Maciel GB, Zeilhofer P. Comparison of capture methods for the diagnosis of adult anopheline populations from state of Mato Grosso, Brazil. Rev Soc Bras Med Trop. 2011:44(5):555-60.

29. Obenauer PJ, Abdel-Dayem MS, Stoops CA, Villinski JT, Tageldin R, Fahmy NT, et al. Field responses of Anopheles gambiae Complex (Diptera: Culicidae) in Liberia using yeast-generated carbon dioxide and synthetic lure-baited light traps. J Med Entomol. 2013:50(4):863-70.

30. Hutchinson RA, West PA, Lindsay SW. Suitability of two carbon dioxide-baited traps for mosquito surveillance in the United Kingdom. Bull Entomol Res. 2007:97(6):591-7.

31. Lee HI, Seo BY, Shin EH, Burkett DA, Lee JK, Shin YH. Efficiency evaluation of Nozawa-style black light trap for control of anopheline mosquitoes. Korean J Parasitol. 2009;47(2):159-65. 